\title{
LA HISTORIOGRAFÍA LOCAL COMO HERRAMIENTA DE RECONSTRUCCIÓN DEL MUNDO FUNERARIO EN COLONIA PATRICIA CORDUBA
}

\author{
LOCAL HISTORIOGRAPHY AS A TOOL TO RECONSTRUCT THE \\ FUNERARY WORLD IN COLONIA PATRICIA CORDUBA
}

ANA B. RUIZ OSUNA*

Resumen: Actualmente la relación entre Arqueología y Ciencia Historiográfica resulta indisociable, algo que no podía pasar desapercibido en la interpretación de los restos romanos de carácter funerario. Las características de una ciudad como Córdoba han centrado la atención de los más prestigiosos eruditos locales desde el siglo XVI, los cuales llevaron a cabo las primeras descripciones de las necrópolis cordubenses, destacando la monumentalidad de los hallazgos.

Gracias a sus obras se ha visto ampliado el conocimiento acerca de los recintos funerarios, hasta hace pocos años casi desconocidos, que se definen, además, como el producto de un complejo proceso de parcelación de los terrenos ubicados en las áreas extramuros más próximas al recinto amurallado. Así se intuye el caso del "Camino Viejo de Almodóvar" (antigua via CordubaHispalis), cuya hipótesis de trabajo ha sido refrendada arqueológicamente gracias a la reciente excavación de un sector funerario en la Avda. de las Ollerías, de la que aquí se ofrecen algunas novedades. Un fenómeno de monumentalización que no fue exclusivo del ámbito urbano, tal como se desprende de los restos reinterpretados como un posible monumento templiforme en el "Camino de Mesta", asociado a alguna villa o centro de producción ubicado a dos kilómetros de la ciudad.

Palabras clave: Historiografía local. Mundo funerario romano. Monumentalización de las necrópolis cordubenses. Gräberstrasse. Recintos funerarios. Parcelación de los terrenos extramuros. Necrópolis septentrional. Monumento templiforme del "Camino de Mesta".

\begin{abstract}
Attualmente la relazione tra Archeologia e Scienza Storiografica risulta indissociabile, un aspetto che non può essere sottovalutato nell'interpretazione dei resti romani di carattere funerario. Le caratteristiche di una città come Córdoba hanno attirato l'attenzione, a partire dal secolo XVI, dei piú prestigiosi eruditi locali, che stilarono le prime descrizioni delle necropoli cordubenses, evidemziando la monumentalità dei reperti.

Grazie alla loro opera è stata ampliata la conoscenza di recinti funerari, fino a pochi anni fa quasi sconosciuti, che si definiscono come il prodotto di un complesso processo di partizione dei terreni ubicati nelle aree extraurbane limitrofe. Così si intuisce nel caso del "Camino Viejo de Almodóvar" (antica via Corduba-Hispalis), la cui ipotesi di lavoro è stata affermata archeologicamente grazie ai recenti scavi di un settore funerario nella Avenida de las Ollerías, dei quali qui di seguito si offrono alcune novità. Un fenomeno di monumentalizzazione che fu non solo esclsivo del ambito urbano, come si apprende dalla reinterpretazione di un possibile monumento templiforme nel "Camino de Mesta", colegato a una villa o a un centro di produzione ubicato a due chilometri di distanza dalla città.
\end{abstract}

Key words: Storiografia locale. Mondo funerario romano. Monumentalizzazione delle necropoli corduneses. Gräberstrasse. Recinto funerari. Partizione di terreni extraurbani. Necropoli Settentrionale. Monumento templiforme del "Camino de Mesta".

\footnotetext{
* Universidad de Córdoba
} 
Hemos de tener en cuenta que la Arqueología, como ciencia interdisciplinar, se nutre de muy diversas fuentes, entre las cuales juega un papel prioritario la revisión de antiguos trabajos y el acercamiento a las fuentes históricas escritas, particularmente las de carácter local (Sánchez 2002: 18). Esta corriente ha experimentado un fuerte impulso en las últimas décadas ${ }^{1}$; así en territorio andaluz destaca la serie dirigida por J. Beltrán y F. Gascó (1993; 1995), la cual nació con el objetivo de "promover y difundir estudios que ilustren la forma en la que se descubrió u olvidó, preservó o destruyó la antigüedad" (Beltrán y Gascò 1995).

Precisamente, las primeras noticias sobre monumentos funerarios en Hispania proceden de las obras de diversos eruditos del siglo XIX, caso de Labaña o Laborde (Cancela 2002: 163). Conocidas son las aportaciones de este último para el conocimiento del monumento de El Daimuz, hoy desaparecido, y la fisonomía original del monumento de Villajoyosa (Abad y Bendala 1985: 147-184). De igual forma, las ilustraciones llevadas a cabo por Accursio en 1526 (Chabret 1888; 1979: 96), durante su viaje a España, han permitido conocer un sepulcro dedicado a varios miembros de la familia Sergia, en Sagunto (Valencia) (Cancela 1993: 247 ss.; 2002: 169).

El acercamiento al mundo funerario de época romana surge de manera evidente en nuestro país a partir del siglo XVI, momento en el que se desarrolla el Humanismo y se configuran importantes catálogos artísticos y de antigüedades. El interés de estas obras presenta una doble vertiente, por un lado, el conocimiento de las propias construcciones sepulcrales o los materiales escultóricos relacionados con ellas; por otro, las inscripciones funerarias. En este último apartado sobresalen las figuras de Francisco Rus Puerta, Martín Jimena Jurado y Ambrosio de Morales, quienes, además de las transcripciones de los tituli sepulchris, aportan el diseño de los soportes (Cancela 2002: 163).

Precisamente, el cordobés Ambrosio de Morales - considerado el preceptor de la historiografía moderna en España y el primer arqueólogo de nuestro país- ha sido objeto de un exhaustivo estudio por parte de S. Sánchez Madrid (2002), donde analiza una de sus principales obras: Las Antigüedades de las Ciudades de España que van nombradas en la Coronica (1577). El valor de la misma reside en su papel de implantadora de la ciencia arqueológica en España, ya que el autor no sólo recurre a las fuentes clásicas para extraer información histórica, sino que valora los restos arqueológicos,

1. Arce y Olmos (coords.) (1991); Beltrán y Gascó (eds.) (1993); Gascó y Beltrán (eds.) (1995); Díaz-Andreu y Mora (coords.) (1997). numismática y epigrafía principalmente (Sánchez Madrid 2002: 26 ss.). En el capítulo dedicado a las Piedras antiguas de Romanos, escritas en latín, de que ay por toda España gran muchedumbre, el erudito valora el soporte epigráfico y los aspectos paleográficos, elaborando una primera tipología a partir de la morfología del soporte y su función ${ }^{2}$ (Sánchez Madrid 2002: 102 ss.). Incluye algunos dibujos que, sin embargo, deben tomarse con precaución, pues aunque parece que la elección del soporte no responde a una pretensión personal ni fruto del azar del autor, no debemos olvidar que se trata de representaciones estereotipadas basadas en una gama preestablecida de modelos monumentales, no tomados de un modo realista del natural (Sánchez Madrid 2002: 111 ss.).

El acercamiento a las fuentes locales de carácter histórico supone, pues, un complemento perfecto para el conocimiento exhaustivo del proceso de monumentalización funeraria en Córdoba durante época romana. Este tipo de estudios permite descubrir restos arqueológicos hasta ahora desconocidos o la fisonomía original de otros que han cambiado con el paso del tiempo; así como datos susceptibles de ser reinterpretados como funerarios bajo nuevas perspectivas. En esta línea se ha trabajado sobre el denominado "Mausoleo de los Pompeyos", en Torreparedones (Baena/Castro del Río) (Beltrán 2000: 133-136)), que conocíamos únicamente a través de las descripciones realizadas por $\mathrm{M}$. de la Corte (1839) y F. de Valverde (1903). De igual forma, el estudio elaborado por J. Beltrán (2002: 459-486) sobre el inédito catálogo histórico-artístico de la provincia de Jaén, elaborado por Enrique Romero de Torres, ha permitido acceder a materiales hoy desaparecidos que se relacionan con el tipo de monumento en forma de edícola del Alto Guadalquivir (Beltrán y Baena 1996). Igualmente, los dibujos aportados por Pérez Bayer han hecho posible plantear la existencia de monumentos en forma de altar, tipología hasta ahora desconocida en la zona jiennense (Baena y Beltrán 2002).

Las características de una ciudad como Córdoba han centrado una especial atención de estudios desde el Renacimiento hasta nuestros días. Destaca la labor a cargo de los más prestigiosos eruditos locales ${ }^{3}$ que en

2. Así, distinguía entre las que ofrecían "medidas de caminos", aras o altares pequeños y "dedicaciones” (Sánchez 2002: 103-111), aunque de todas debemos destacar, por relevantes para nuestro estudio, las que distinguió como piedras antiguas Romanas de sepulcros, conjunto que según el erudito mantenía unas características comunes (Sánchez 2002: 104).

3. Pedro Díaz de Ribas, De las antigüedades y excelencias de Córdoba, 1627; Padre Martín de Roa, Antiguo Principado de Córdoba en la España Ulterior o Andaluz, 1636; Andrés de Morales y 
su intento de configuración de una historia general recogieron noticias de hallazgos arqueológicos, así como extensas relaciones de epígrafes, entre los que destacan -por el número conservado- los de naturaleza funeraria. Así, Francisco Ruano en su Historia General de Córdoba (1760) lleva a cabo una descripción de las excelencias que acoge la provincia de Andalucía para a continuación elaborar una relación de las ciudades romanas de la Bética, siguiendo principalmente a Plinio. Por otra parte, en Historia de Córdoba desde los más remotos tiempos hasta nuestros días, de Luis de Maraver y Alfaro (1863), se abordan los orígenes de Corduba hasta la caída del Imperio Romano, aludiendo a sucesos acaecidos durante este mismo período en el resto de Hispania y el Mediterráneo.

Al adentrarse en el caso concreto de Córdoba, la mayoría de estudiosos se refieren a una serie de cuestiones fundamentales que se repiten a lo largo de sus escritos, tales como la ubicación de la Corduba indígena, la fundación romana a manos de Claudio Marcelo, la localización de Munda o la descripción de los principales monumentos de la ciudad. Bartolomé Sánchez de Feria (1772: 118 ss.) es el único que define una importante área funeraria de época romana ubicada al Norte de la ciudad, concretamente en "el Real Convento de la Merced, todo aquel Campo hasta el del Carmen Descalzo, y mas abaxo de la Merced, el sitio de Texares, y la Huerta de la Reyna", donde sitúa "el Osario, cuyo nombre conserva la puerta de la Ciudad, que está en frente de este campo. Pero este Osario no debemos creer fuese el comun, y propio de la Gente Plebeya, y Peregrinos, sino el de Personas Ilustres, y principales semejante al del Campo Marcio en Roma. En este sitio, pues, se han hallado, y encuentran frequentisimamente muchos, y grandes sepulcros labrados, yá anzia la Torre Malmuerta, yá anzia los Texares, Huerta de la Reyna, \&c. Varios de estos sepulcros se han visto primorosos, y muchos como de familias enteras, y en algunos quatro cadaveres, y muchas inscripciones sepulcrales. Todo lo que prueba ser sitio de entierro de personas distinguidas, y no de la plebe"4. La

Padilla, Historia de Córdoba, 1662; Francisco Ruano, Historia General de Córdoba, 1760; Bartolomé Sánchez de Feria, Palestra Sagrada o Memorial de los Santos de Córdoba, 1772; Luis Ramírez de las Casas-Deza, Indicador Cordobés. Manuel histórico topográfico de la ciudad de Córdoba; Luis Maraver y Alfaro, Historia de Córdoba desde los más remotos tiempos hasta nuestros días, 1863; Teodomiro Ramírez de Arellano, Paseos por Córdoba. O sean apuntes para su historia, 1873.

4. Efectivamente, el territorio delimitado coincide con una parte de lo que hoy se ha definido convencionalmente como Necrópolis Septentrional, identificada durante mucho tiempo con la necrópolis patricia, en detrimento de la Occidental que fue calificada como investigación actual pone de manifiesto que esta zona, generada en el entorno del Item a Corduba Emeritam (Melchor 1995), fue una de las más utilizadas por las elites locales para la ubicación de sus tumbas, tal vez por la simbología minera, fuente de su riqueza en muchos casos (Ruiz Osuna 2007: 131 ss.). Así lo corroboran los hallazgos de carácter sepulcral, como la cámara funeraria conservada en los sótanos del Palacio de la Merced (Vaquerizo 1996: 194-198; 2001a: 140 ss.; 2001b: 210) y otros descubiertos en recientes intervenciones arqueológicas en el entorno de la Torre de la Malmuerta (González 1992; Carmona, Moreno, Bermúdez 1997: 28 y 33-34), Vial Norte (Ibáñez et alii 1990; Murillo et alii 1998), barrio de El Brillante (Ruiz Nieto 1995; 1996; 1997a; 1997b; Penco 1997a; 1997b 1998; Salinas 2004a; 2004b) y Avda. de las Ollerías (Baena 1989a; 1989b; Penco et alii 1993; Marfil 1997; López 2006); dibujando un paisaje que, según García y Bellido (1963: 171), estaba poblado de "tumbas y mausoleos más o menos monumentales de los que ya no es posible formarse idea cabal" (Fig. 1).

De estos enterramientos monumentales ya nos daba cuenta Luis Maraver y Alfaro (1863: 314 ss.) al describir un interesante hallazgo acaecido en 1744, junto a la Puerta de Osario. Se trata de nueve sepulcros que se organizaban "en dos grupos, uno se componía de cinco enterramientos, más ordinariamente de piedra caleña (...), el otro grupo estaba algo más apartado, quedando el pozo en medio, y se componía de cuatro de más esmerada construcción, trabajados con jaspes de varias clases, y de ellos era uno más corto y como de mujer, guarnecido por su cara interior, con preciosas tablas de jaspe blanco, perfectamente pulimentadas, y de una pulgada de gruesas. En todos estos sepulcros habia esqueletos y varias inscripciones de las que se deduce que debió ser el enterramiento de la familia Caninia $y$ de dos libertos que tomaron el nombre del primero". Resulta imposible identificar el tipo de enterramiento, tal vez un grupo de cistas de piedra, recubiertas al interior con placas de mármol, que se situarían tanto de forma aislada como conjunta, formando parte de una construcción funeraria mayor, al estilo de las excavadas en el Parc de la Ciutat (Tarragona) (T'Eda 1987). Según D. Vaquerizo (2002), esta tipología de tumba presenta su máximo desarrollo entre los siglos III y VI d.C., lo que contrasta con la cronología augustea de la inscripción perteneciente a la gens Caninia $\left(C I L, \mathrm{II}^{2} / 7\right.$,

plebeya. Una idea que retomaría tiempo después Santos Gener (1955) y que en algunos casos ha perdurado hasta la actualidad, quedando hoy fuera de toda argumentación gracias a los hallazgos de las últimas décadas. 


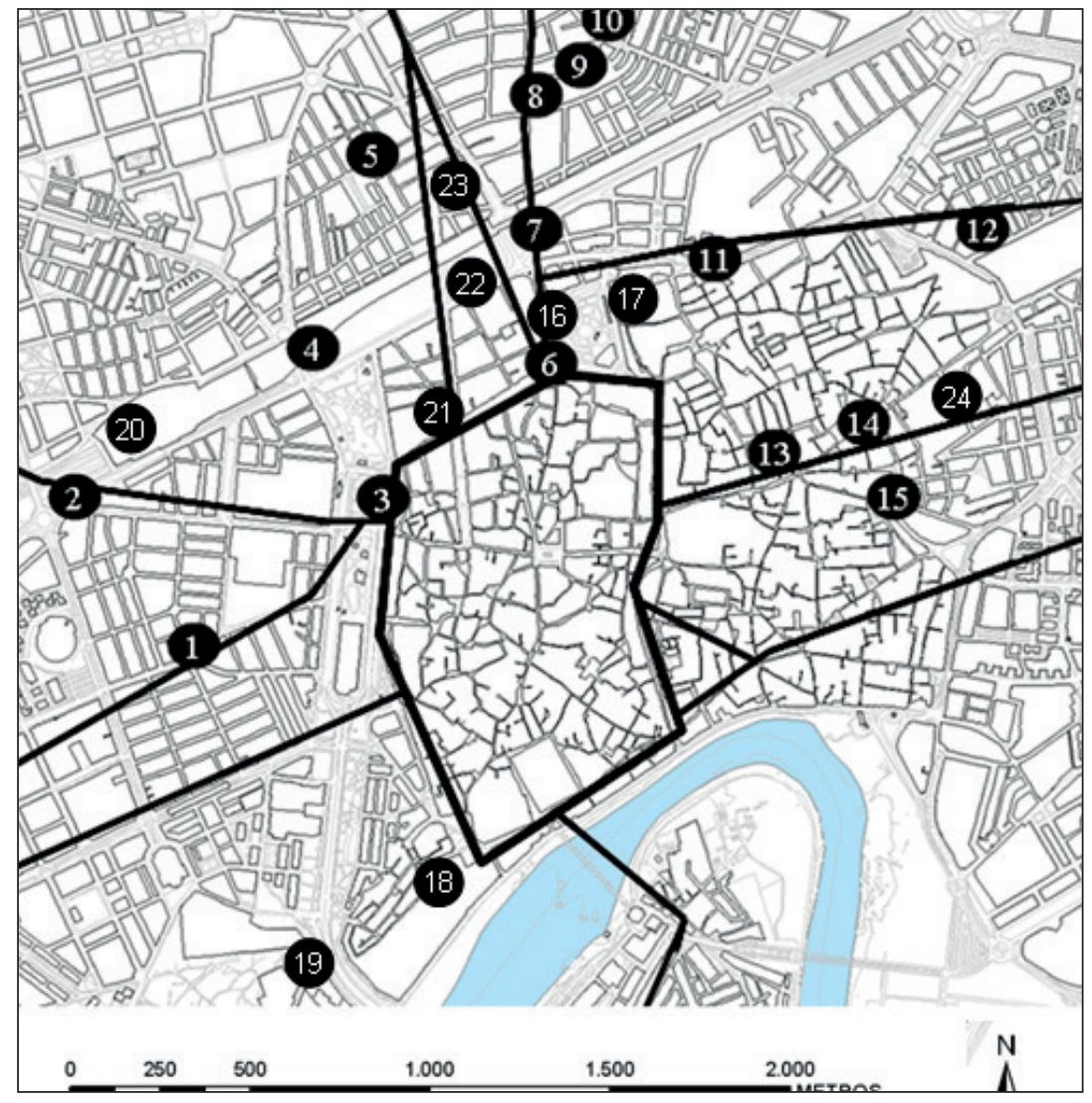

Figura 1. Vestigios de monumentalización funeraria en Colonia Patricia. 1. "Camino Viejo de Almodóvar" 2. Ibn-Zaydun 3. Puerta de Gallegos 4. Vial Norte 5. La Constancia 6. Ronda de los Tejares 7. Camino del Pretorio 8. Manzana Banesto 9. El Avellano 10. Santa Rosa 11. Avda. de las Ollerías 12. Marrubial 13. C/ San Pablo 14. C/ Realejo 15. C/ Muñices 16. Palacio de la Merced 17. Torre de la Malmuerta 18. Alcázar RR.CC. 19. Avda. Corregidor 20. Cercadilla 21. Avda. Gran Capitán 22. Avda. América 23. C/ Abderraman III 24. San Lorenzo
434). Las características formales y tamaño de esta última permite plantear su ubicación en una construcción de obra, como así confirman los restos de ganchos metálicos en la parte superior de la misma. Nos encontraríamos, pues, ante un claro ejemplo de temprana inhumación en Córdoba (Vaquerizo, e.p.) o ante una reutilización de materiales en ambientes funerarios de época tardía (Ruiz Osuna 2007: 97 ss.).

La atención prestada a la labor desarrollada por estos eruditos cordobeses ha permitido plantear la existencia de varios monumenta de los que, hasta ahora, no se tenía conocimiento alguno. Este es el caso de una supuesta edícola, perteneciente a varios libertos de $\mathrm{Ti}$ tus Nerius $\left(C I L, \mathrm{II}^{2} / 7,501\right)$, que se encontraría bajo la torre campanario de la actual Iglesia de San Andrés ${ }^{6}$ (Vaquerizo 2002: 181). Igualmente se ha hipotetizado

5. Un ejemplo claro es la reutilización de varios fragmentos arquitectónicos y un friso con guirnalda de época augustea en una tumba de inhumación del siglo III d.C. hallada en la C/ Abderramán III (Córdoba) (Vicent 1972-74: 113-124).

6. "'hallaron entonces alli dos estatuas consulares, varios fragmentos de idolos, y de columnas romanas, que se consumieron en el Edificio" (Francisco Ruano 1760). sobre una tumba de mármol blanco en la Avda. del Marrubial $^{7}$ (Vaquerizo 2002: 180), un columbario en la Huerta de Machaquito (Avda. Cruz de Juárez) (Vicent y Sotomayor 1925: 209), la cimentación de un posible edificio turriforme con decoración de Attis funerario en la Avda. de América y un recinto funerario en el barrio de la Sagrada Familia (Santos Gener 1947: 90 ss., lám. XXVIII 1 y 2; 1950: 56, $\mathrm{n}^{\mathrm{o}}$ 5).

Pero el fenómeno de la muerte no fue privativo de ambientes urbanos, sino que también se manifiesta en terrenos alejados de la ciudad, de carácter privado, asociados a villae o centros de producción. En esta línea se sitúan los restos excavados por E. Romero de Torres en el denominado "Camino de Mesta", a unos 2 $\mathrm{km}$ al Este de Córdoba (Fig. 2). La excavación, llevada a cabo en 1928, dio cuenta de una potente cimentación a base de grandes sillares de planta rectangular $-3 \mathrm{~m}$ de largo x $2.50 \mathrm{~m}$ de ancho- orientada según

7. “(...) sacando barro para las ollerías en el sitio llamado el Marrubial (...) de mármol blanco, y en él una olla con huesos y muchos carbones. También había en él muchos brinquillos o juguetes de barro o vidrio, que se destruyeron en mayor parte al descubrirse" (Maraver y Alfaro 1863: 353-354). 
los puntos cardinales, con una ligera desviación NESO (Romero de Torres 1929: 8). Un sillar superpuesto en el ángulo NE de la cimentación es el único vestigio de alzado conservado, que debió estar construido en opus quadratum. Aunque resulta imposible establecer la tipología de este edificio romano hemos de suponerlo ricamente decorado, tanto en el exterior como en el interior ${ }^{8}$ (Ruiz Osuna 2007: 92). Entre los hallazgos más importantes reza la mitad inferior de una escultura femenina cubierta con un largo chitón ceñido (Fig. 2c). A. García y Bellido (1949: n 245, 202-203, Lám. 170), por comparación con modelos orientales del Museo de Smyrna, la fechó en el siglo II d.C. Aunque responde al tipo de estatuas femeninas acéfalas y carentes de atributos, su excavador la identificó con una representación de la diosa Ceres (Romero de Torres 1929: 10). Ciertamente, su vestimenta remite a la representación de alguna deidad, lo que sumado a los restos de espiga que aparecen cerca del pulgar de una mano de mármol, procedente de las mismas excavaciones y, seguramente, perteneciente a la escultura, hace pensar en su atribución a tal diosa, protectora de la agricultura, que solía ser representada con una cornucopia, antorcha, un arado o un haz de espigas.

Fue, sobre todo, en el siglo II d.C. cuando en la estatuaria funeraria romana comienza a observarse un proceso de divinización, por el cual el retrato de la difunta era colocado en una estatua con los atributos propios de algunas divinidades, en especial Venus y Ceres (Hesberg 1994: 236). Una práctica conocida como consecratio in formam deorum que nació en círculos libertinos italianos, pero que pronto se difundió entre las capas más altas de la sociedad, alcanzando, según A. U. Stylow (2002: 359), gran popularidad en las provincias hispanas, sobre todo al Sur de la Lusitania y al Oeste de la Baetica. Nuestra posible Ceres podría responder al retrato de la difunta, que habría sido colocado al interior de una cámara funeraria o expuesta en una columnata de fachada, acompañada, posiblemente, de otras figuras, tal como demuestra un conjunto de pliegues perteneciente a una toga o manto, que pendería del brazo izquierdo de una escultura exenta (López López 1998).

Aunque los restos fueron identificados en principio con los de una posible villa o templo romano de bastante importancia (Romero de Torres 1929: 9), el hallazgo de varias arae y estelas funerarias podrían

8. Así lo demuestran los elementos de decoración arquitectónica y escultórica, recogidos durante la excavación, concretamente, un fragmento de arquitrabe (Márquez Moreno 1998: nº 272, lám. 23), varias losetas de mármol destinadas a pavimento y restos de figuras vestidas exentas (Ruiz Osuna 2007: 92 ss.) plantear su interpretación como un monumento funerario $^{9}$ (Ruiz Osuna 2007: 94). La tipología, imposible de precisar, puede asociarse con monumentos templiformes -caso de los conocidos en Fabara, Caspe o Chiprana (Cancela 2002: 163-180)- o de tipo edícola que cuentan, generalmente, con fachadas porticadas y esculturas que representan las imágenes de los propietarios. Nuestro monumento pudo contar además con un recinto que delimitara el locus religiosus ${ }^{10}$, supuesto gracias a las cimentaciones en opus quadratum de varios lienzos paralelos a la estructura rectangular que parece ser permaneció sin ningún tipo de cerramiento en su lado meridional(Fig. 2b) (Ruiz Osuna 2007: 94), lugar hacia donde abriría la fachada de la construcción, creando así un auténtico marco escenográfico ubicado en las cercanías del puente Pedroches (Melchor 1995: 205 ss.), por tanto, junto a la via Augusta a su llegada a Córdoba ${ }^{11}$.

Por su parte, la existencia en la antigua Córdoba romana de recintos funerarios era ya conocida gracias a los testimonios epigráficos con indicación de la peditura, que nos ilustran acerca de acotados con unas superficies variables entre los 12 × 12 y 20 x 20 p.r. Las medidas resultan algo inferiores con respecto al resto de Hispania, pero similares a las localizadas en Roma, lo que ha sido interpretado como el resultado de una posible parcelación en lotes de los terrenos funerarios, muy necesaria en una ciudad capital de conventus y Provincia, con evidentes problemas de superpoblación (Vaquerizo 2001a: 177; 2002: 168). El conocimiento de algunos epígrafes con indicación del locus sepulchris, hoy desaparecidos (Morales 1577: folio 14; Ruano 1760; Maraver y Alfaro 1863: 354-355), permiten corroborar las superficies indicadas, así como un uso variado del formulario destinado a indicarlas (vid. Tabla 1).

9. Una reinterpretación que también ha sido aplicada a los restos de El Sotillo, en Alfaro, situados a un kilómetro de la ciudad romana de Graccurris (Hernández Vera et alii 1999), en el margen izquierdo del río Alhama, al pie de una via y muy cerca de la necrópolis de la Azucarera, ubicación similar a los restos de la Venta de Pedroches. Considerados en principio como parte de un pequeño templo han sido recientemente identificados con los restos de un monumento funerario en forma de altar (Vaquerizo 2001a: 147, nota 37; 2002: 190, nota 94).

10. La práctica de señalizar el área sepulcral fue de vital importancia en ámbitos rurales (Vaquerizo 2001a: 172) donde existían tumbas aisladas que debían ser individualizadas con respecto a su entorno por miedo, entre otras causas, a desaparecer en caso de ser vendido o desmembrado el fundus privado en que se inscribían.

11. Esta simple hipótesis de trabajo sólo podría confirmarse tras un detenido estudio de los materiales conservados. Lamentablemente, la falta de medios y personal que sufre el Museo Arqueológico y Etnológico de Córdoba, sumada a la desaparición de gran parte de los materiales, dificulta esta tarea. 

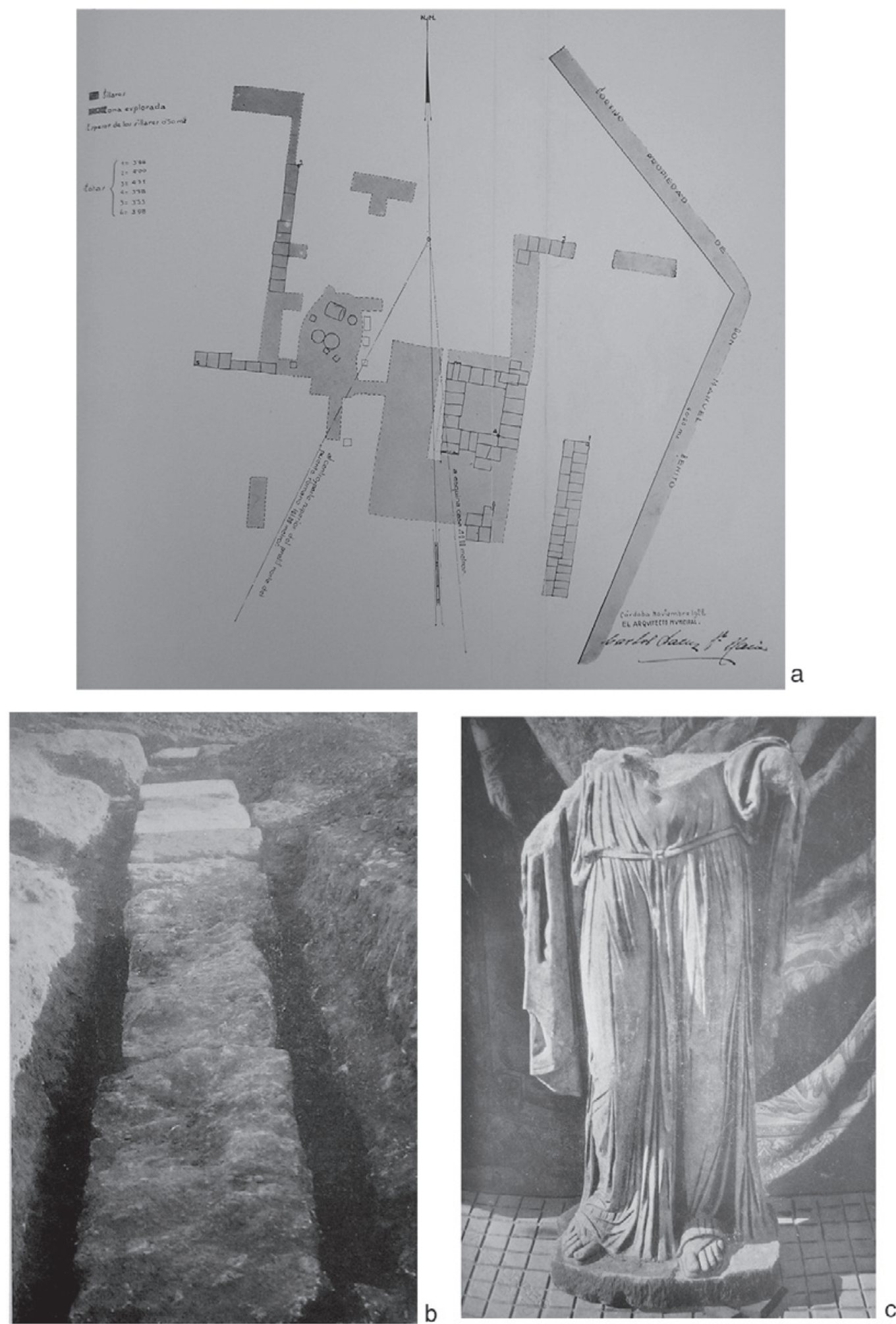

Figura 2. Estructuras y estatua femenina documentadas en el "Camino de Mesta" o "Venta de Pedroches" (Romero de Torres, 1929) 
Tabla 1. Indicaciones superficiales de loci sepulturarum documentados hasta la fecha en Córdoba. Elaborado a partir de Vaquerizo 2001a: 176, Tabla II.

\begin{tabular}{|c|c|c|c|}
\hline$C I L \mathrm{II}^{2} / 7699 \mathrm{~b}$ & Caserío de San Pablo & L(ocus) P(edum) & $20 \times 20$ pies \\
\hline CIL II'2/7 517 & San Benito & $\begin{array}{l}\mathrm{L}(\text { atum) in fr(onte) } \mathrm{p} \text { (edes) } \\
\mathrm{L} \text { (ongum) in ag(ro) } \mathrm{p} \text { (edes) }\end{array}$ & $15 \times 15$ pies \\
\hline$C I L \mathrm{II}^{2} / 7465$ & C/ José $\mathrm{M}^{\mathrm{a}}$ Herrero & L(ocus) P(edum) & $12 \times 12$ pies \\
\hline CIL II'/7 486 & Camino Viejo de Almodóvar & L(ocus) P(edum) & 12 pies \\
\hline$C I L \mathrm{II}^{2} / 7547$ & El Brillante & quoquo versus/p(edes) & 12 pies \\
\hline López 2006 & Avda. de las Ollerías & L(ocus) P(edum) & 12 pies \\
\hline López 2006 & Avda. de las Ollerías & L(ocus) P(edum) & 12 pies \\
\hline López 2006 & Avda. de las Ollerías & L(ocus) P(edum) & 12 pies \\
\hline Ruano (1760) & Desconocida & $\begin{array}{l}\text { In F(ronte) } \mathrm{P} \text { (edes) } \\
\text { In } \mathrm{A} \text { (gro) } \mathrm{P} \text { (edes) }\end{array}$ & $15 \times 15$ pies \\
\hline $\begin{array}{c}\text { Maraver y Alfaro } \\
\qquad(1863)\end{array}$ & $\begin{array}{c}\text { Heredad de los Padres de la Compañía } \\
\text { de Jesús }\end{array}$ & $\begin{array}{l}\text { In F(ronte) } \mathrm{P} \text { (edes) } \\
\text { In A(gro) } \mathrm{P} \text { (edes) }\end{array}$ & $12 \times$ ? pies \\
\hline
\end{tabular}

Del mismo modo, resultan interesantes las nuevas interpretaciones de restos sumamente conocidos, como las estructuras en opus quadratum (Fig. 3a) (Santos Gener 1955: 13 y 19) y la cámara funeraria (Fig. 3b) (Romero de Torres 1941: 323 ss.) procedentes del "Camino Viejo de Almodóvar". En una última revisión al tema (Vaquerizo 2001b: 137 ss. y 152), las primeros fueron identificadas con posibles recintos a cielo abierto, mientras que el monumento fue dotado de un amplio recinto pavimentado con losas de piedra caliza ${ }^{12}$. El análisis exhaustivo de los trabajos arqueológicos llevados

12. “(...) medio metro más abajo del nivel actual de la carretera se descubrieron varias losas rectangulares de piedra caliza de gran tamaño y de 0,15 m espesor, que se unían a la plataforma o basamento que existe encima de la bóveda de la tumba, sobre el que se elevaría algún importante monumento, cuyas losas pertenecieron, sin duda, a la primitiva pavimentación que lo rodeaba. Algunas de estas losas, atravesaban en sentido oblicuo el camino, a medio metro bajo el firme de grava, y aparecieron cortadas en la cuneta del lado opuesto, o sea, en la parte derecha de la carretera, donde practicada otra exploración, se hallaron cuatro grandes sillares labrados de piedra franca unidos en línea recta sin mezcla ni trabazón alguna; tres tenían, aproximadamente, la misma medida, 1,15 m de largo por 0,60 de alto y 0,50 de ancho; el cuarto era más pequeño y estaba casi destrozado; todos descansaban sobre tierra virgen y probablemente pertenecerian a un recinto funerario (...)" (Romero de Torres 1941: 324 ss.). a cabo por E. Romero de Torres en este lugar ha permitido confirmar estas primeras intuiciones (Ruiz Osuna 2005: 79-104).

Las excavaciones ocuparon un total de 18 hectáreas, es decir, prácticamente la totalidad de la antigua "Haza de la Salud"13 , donde, además de un gran número de enterramientos y restos de posibles ajuares funerarios, se descubrieron, aunque en bastante mal estado de conservación debido al proceso de expolio (Santos Gener 1955: 11), multitud de vestigios de naturaleza arquitectónica identificados por su propio excavador como " $d e$ partamentos" o "estancias funerarias" (Fig. 4 y 5).

Con los datos recabados ha sido posible plantear la existencia de hasta 12 recintos funerarios realizados, principalmente, en opus quadratum -algunos con sillares almohadillados- $\mathrm{y}$ dispuestos de forma paralela a

13. La antigua "Haza de la Salud" (actual barrio de Ciudad Jardín), quedaba limitada al Norte por el "Camino Viejo de Almodóvar" (hoy, C/ Antonio Maura); al Este por el "Callejón de la Hoya" (lugar donde se ubica el Grupo Escolar Enríquez Barrios); al Oeste por el "Callejón de Chinales" (actual Avenida de Gran Vía Parque); y al Sur por la fábrica de luz eléctrica y el camino que conducía al "Cortijo de Majaneque", también conocido como "Camino Nuevo de Almodóvar", y que hoy podemos identificar con la Avenida del Aeropuerto. 


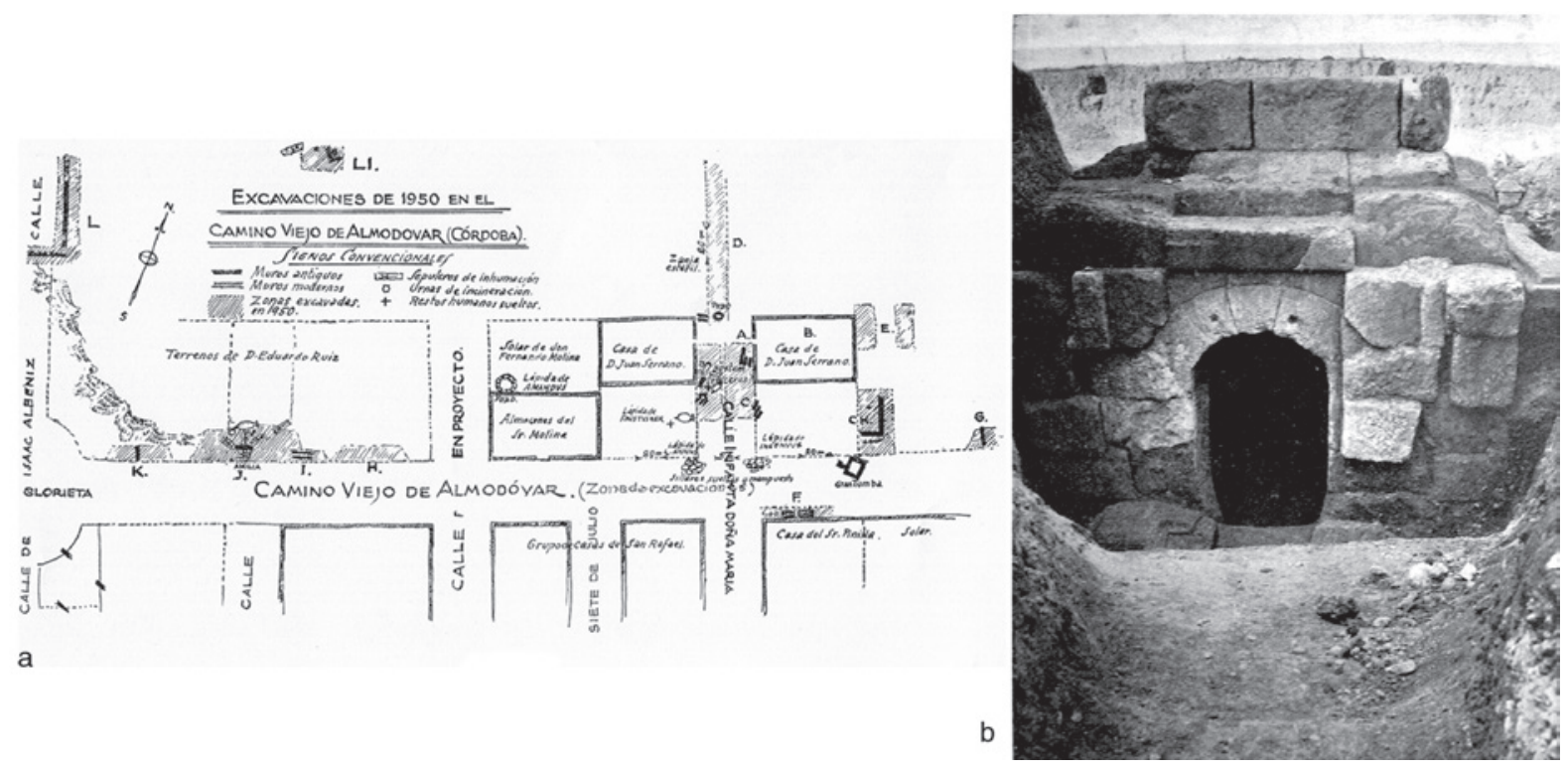

Figura 3. "Camino Viejo de Almodóvar" a) Planimetría de las excavaciones de Santos Gener (1955, Fig. 2) b) Cámara funeraria en el momento de su descubrimiento (Romero de Torres 1941)

la via Corduba-Hispalis, pero de los que desconocemos su fisonomía original y su altura completa, ya que la mayoría presentaban una única hilada (Ruiz Osuna 2005: 98). En general, estaban pavimentados -algunos de forma lujosa (mármol) y otros empleando materiales más sencillos (ladrillos o simples suelos de mortero) ${ }^{14}$ y ricamente decorados, como así podrían indicar los abundantes restos de estuco de colores ${ }^{15}$ y los fragmentos de decoración arquitectónica (cornisas, quicialeras) recogidos en el entorno (Ruiz Osuna 2005: 98).

Aunque gran parte de los recintos documentados en Hispania se caracterizan por presentar un perímetro completamente cerrado, existen casos en los que su acceso se realizaba a través de una puerta de entrada, tal y como puede apreciarse en los recintos de los Voconii y de los Iulii, en Mérida (Bendala 1972: 223-254). Así parece ocurrir también en el denominado "Recinto H" donde, entre los muros que lo conformaban, aún se hallaba in situ el escalón de mármol (con los huecos de las quicialeras en sus extremos) que daba paso a la estancia

14. Al igual que otros recintos documentados en muchas necrópolis italianas (Kockel 1983; Floriani Saquarciapino 1958; via Ostiense: Tumbas $\mathrm{n}^{\circ} 13$ ó 17; via Laurentiana: Tumbas 8, 10 ó 15) o de Hispania (Aranegui 1995 197; Silliéres 1997: 195, fig. 107; Bejarano 2000; Estévez 2000).

15. Entre los restos de estuco recuperados en las campañas de excavación de Enrique Romero de Torres destacan "varios fragmentos de estuco pintado, uno con hojas", recogidos junto al monumento funerario descubierto en 1931, del que podría haber constituido su revestimiento interior (Ruiz Osuna 2005: 98).
(Ruiz Osuna 2005: 98). La existencia de un recinto con puerta de entrada resulta de especial importancia por ser uno de los pocos casos documentados en Córdoba ${ }^{16}$ y porque, además, nos certifica la apertura de la fachada a la vía principal.

Los edificios suelen presentar unas medidas similares, que oscilan entre los 2,5 y $4 \mathrm{~m}$ de anchura, equivalentes a estancias de 12 a 17 p.r. de fachada (Ruiz Osuna 2005: 83 ss.), unas medidas acordes con las loci mensurae presentes en la epigrafía funeraria cordobesa $^{17}$ (vid. Tabla 1). Entre estos acotados de medidas estándar se articularían otros de proporciones mayores; es el caso del "Recinto A" y "Recinto C", con muros de 15 y $20 \mathrm{~m}$ de largo, respectivamente. El primero formaría parte de un gran complejo funerario que incluía, entre otros enterramientos menores, la famosa cámara hipogea; por su parte, el segundo contaba en sus terrenos con un posible ustrinum de grandes dimensiones, lo que nos lleva a interpretarlos como espacios de uso colectivo pertenecientes a una familia o un collegium (Ruiz Osuna 2005: 99).

Este paisaje funerario se completaba con la presencia de otras tumbas de carácter más sencillo ubicadas en los

16. Otros casos son el de C/ San Pablo, 17 (Ruiz Nieto 1999a; 1999b) y el recientemente excavado en la Ronda del Marrubial (Penco 2004)

17. Dos de las inscripciones funerarias aparecidas en las cercanías del "Camino Viejo de Almódovar" (CIL, II ${ }^{2} / 7,465$ y 486) hacen referencia a recintos de 12 p.r. 


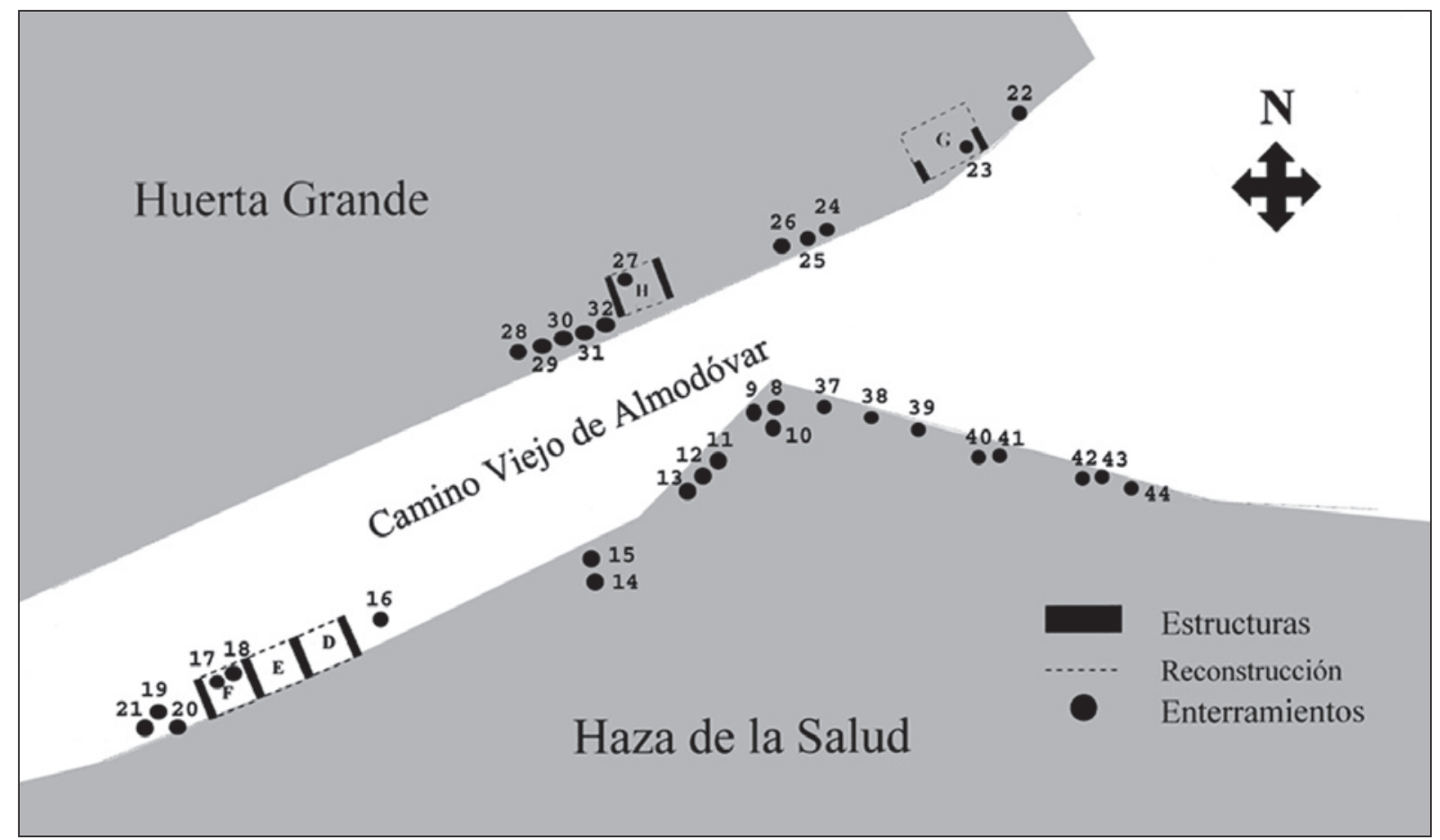

Figura 4. Plano de dispersión de los enterramientos localizados en el sector occidental del "Camino Viejo de Almodóvar"

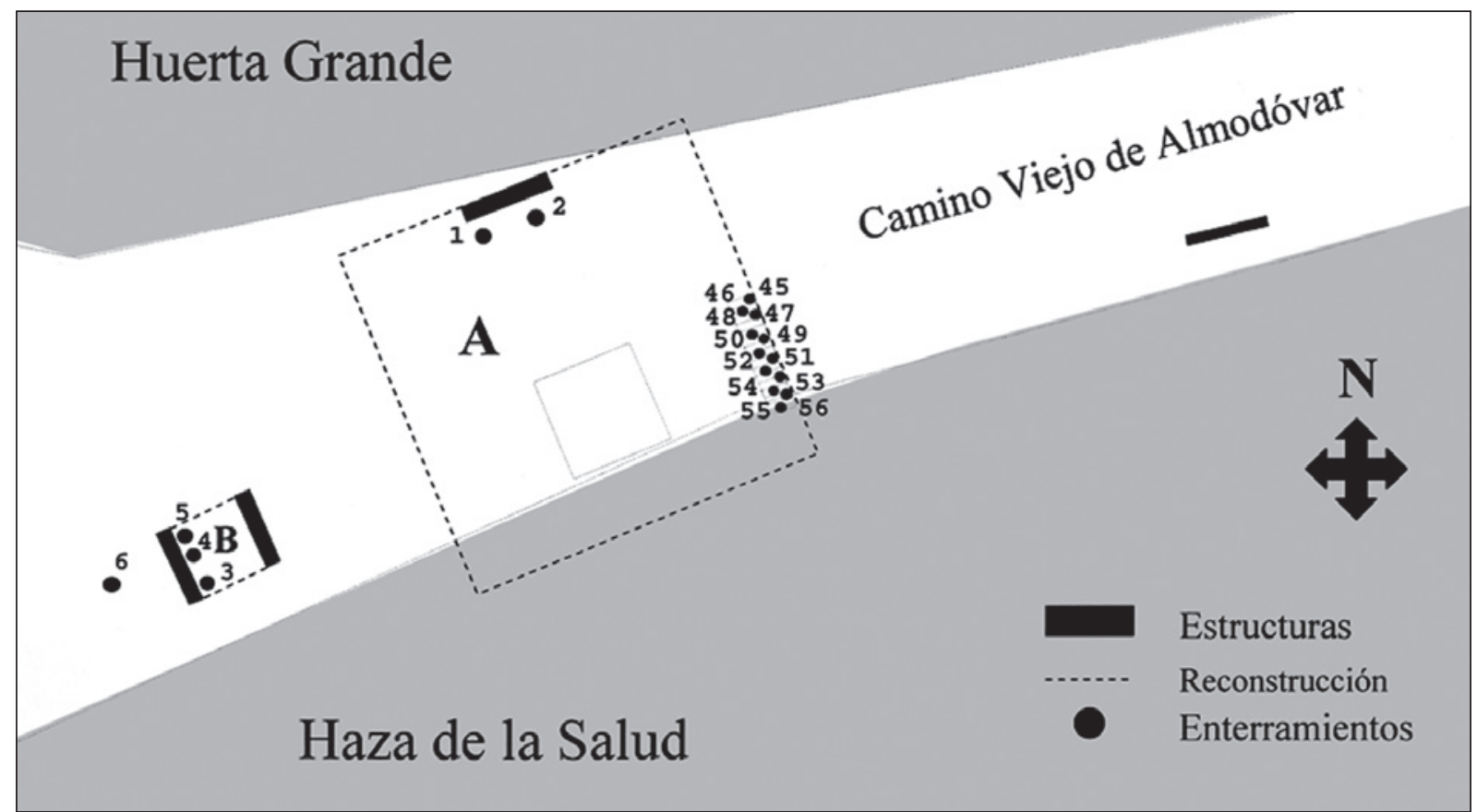

Figura 5. Plano de dispersión de los enterramientos localizados en el sector oriental del "Camino Viejo de Almodóvar" 
espacios libres existentes entre recintos y monumenta, al igual que ocurre en otras necrópolis del Imperio (Calza 1940; Floriani Squarciapino 1959) y de Hispania (Remesal 1979). Por lo que se refiere al rito, existe un claro predominio de las cremaciones frente a las inhumaciones ${ }^{18}$. El autor de las excavaciones no ha dejado apenas referencia sobre superposiciones de enterramientos o distribuciones de carácter espacial; únicamente las inhumaciones parecen agruparse de forma más abundante en el sector Nordeste del "Haza de la Salud". Son, en general, enterramientos de carácter muy sencillo que se ajustan a las tipologías habituales detectadas en las necrópolis de Colonia Patricia durante época altoimperial (Vaquerizo 2002: Fig. 6, Fig. 7A, Fig. 7B, Fig. 8). Sólo las urnas de tradición indígena con tapadera nos ofrecen una cronología más precisa, puesto que se corresponden con el subtipo Ia establecido por B. García Matamala (2002-2003: 254-256), datado entre el último cuarto del siglo I a.C. y primera mitad del siglo I d.C.

Los enterramientos más simples corresponden a cremaciones depositadas directamente en el suelo, sin ningún tipo de estructura de protección ni contenedor funerario. Suelen aparecer de forma aislada en el terreno, a priori, sin relación alguna con las estructuras arquitectónicas. No ocurre así con las cremaciones en ollas o urnas, las cuales aparecen prácticamente en todos los casos en el interior de los que han sido definidos como recintos funerarios, lo que podría ilustrarnos acerca de diferencias económicas entre los difuntos (Ruiz Osuna 2005: 100).

Las cistas de piedra caliza representan la tipología más numerosa de este sector de la Necrópolis Occidental, localizándose tanto en el interior de los supuestos recintos como de forma aislada en el terreno. Lo interesante del tipo es que en la mayoría de los casos se presentan formando conjuntos, manifestando así posibles relaciones, familiares o no. Igualmente, cabe señalar una concentración de inhumaciones en ánfora en las inmediaciones del "Recinto F" (Ruiz Osuna 2005: 100).

El mal estado de conservación de la necrópolis y la metodología de excavación empleada apenas permitieron recoger restos materiales asociados de forma directa con las tumbas, lo que impide establecer una evolución cronológica de las mismas. Los hallazgos documentados aparecieron esparcidos por toda la zona y bastante revueltos, por lo que resulta imposible determinar un ajuar-tipo (Ruiz Osuna 2005: 101). Pero, la constante referencia a cerámica de producción indígena y de barniz negro nos sitúa en fechas tempranas,

18. De estas últimas casi la mitad corresponden a individuos infantiles. en torno al siglo I d.C. Marco cronológico que corroboran los hallazgos procedentes de las excavaciones en la zona de Samuel de los Santos Gener (1955), que ponen de manifiesto la existencia de un ajuar basado en la sigillata hispánica precoz (García Matamala 2002-03, 263 ss.), al igual que los detectados en "La Constancia" (Vargas 2002: 297-310).

De todo lo anterior se desprende que los individuos enterrados a lo largo del tiempo en el "Camino Viejo de Almodóvar" debieron pertenecer, en general, a estratos sociales similares ${ }^{19}$ (no elevados, pero tampoco por ello necesariamente humildes); entre los cuales, las únicas referencias socio-económicas apreciables vendrían determinadas por la presencia de ajuar funerario y por la inclusión de su enterramiento en el marco de un recinto de obra (Ruiz Osuna 2005: 102). Relaciones que la epigrafía funeraria también se ha encargado de demostrar por medio de las asociaciones entre libertos de distintas familias, a través de las cuales se aseguraban un enterramiento digno (CIL, II $\left.{ }^{2} / 7,454 / 5\right)$, así como la existencia de un posible collegium funeraticium gladiatorium (CIL, II'2/7, 353-369).

Como hemos señalado anteriormente, la alta demanda de espacio funerario en una ciudad como Colonia Patricia, capital de conventus y Provincia, habría promovido grandes programas edilicios en sus diversas necrópolis. Así se intuye en el caso apenas expuesto, el cual encuentra su refrendo arqueológico en una reciente excavación llevada a cabo en la Avda. de las Ollerías (López 2006) (Fig. 6). Tras la preparación propia del terreno, como se desprende de la paridad de cotas existente entre un extremo y otro de la intervención, tuvo lugar la disposición de varias vías secundarias de carácter eminentemente funerario, paralelas a la via Augusta. Sin embargo, únicamente ha sido posible establecer con seguridad uno de estos viales, con un recorrido E-O, al que abren fachada toda una serie de recintos contiguos con medidas semejantes de 12-15 p.r. in fronte y 12 p.r. in agro.

Salvo dos recintos construidos en opus quadratum, la mayoría emplea la técnica del opus incertum a base de un conglomerado de mampostería y cantos de río dispuesto entre cipos, que actuarían a modo de tirantas, conformando una especie de opus africanum (Sánchez y Vaquerizo, e.p.). Es posible que contaran con puertas de acceso abiertas a la propia vía funeraria, como se desprende de los propios hitos, interpretados a la

19. La mayoría de inscripciones recogidas en el CIL $\mathrm{II}^{2} / 7$ como procedentes de la zona pertenecen a gentes de un nivel social no demasiado elevado, generalmente libertos (CIL II ${ }^{2} / 7331,340$ y 454/5) y esclavos (CIL II ${ }^{2} / 7404,463$ y 530). 


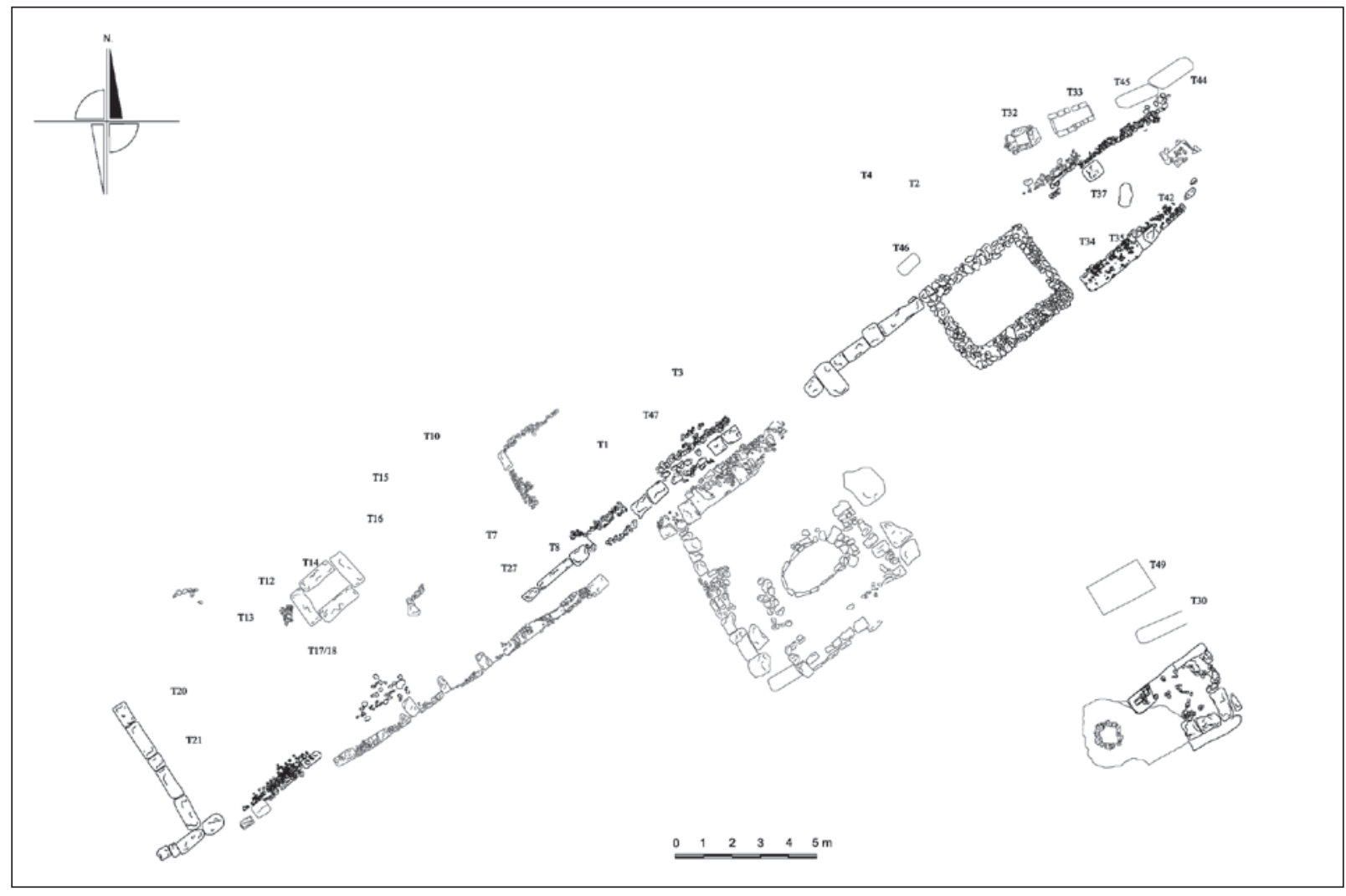

Figura 6. Planimetría de la Avda. de las Ollerías (López 2006). Las estructuras en negro pertenecen a la fase monumental de la necrópolis, datada en el siglo I d.C.

manera de grandes jambas (Sánchez, Vaquerizo, e.p.) (Fig. 7). Si tenemos en cuenta otros ejemplos conocidos, los recintos pudieron quedar completamente abiertos en su fachada, pero protegidos por medio de una cancela metálica (Verzár-Bass 2005: 228).

Las dimensiones y técnica constructiva de estos recintos demuestran una gran uniformidad, sin llegar a ser idénticos, lo que nos ilustra acerca "de un cierto afán por individualizarlas"20 (Sánchez y Vaquerizo, e.p.). Podríamos, así, establecer la existencia de "empresas especializadas en la construcción de tumbas "en serie”, luego vendidas de forma independiente" (Sánchez y Vaquerizo, e.p.), tal y como se ha planteado para La Constancia (Vaquerizo, Garriguet y Vargas 2005) o el sector funerario de la $\mathrm{C} /$ Muñices, esquina con Plaza de la Magdalena (Liébana y Ruiz 2006: 297-324).

En el caso que nos ocupa los recintos cuentan con una profundidad semejante de 12 p.r. in agro, de ahí

20. La posesión de recintos de iguales medidas y características no cumpliría con el afán de representación que se perseguía en este tipo de manifestaciones funerarias. que los cipos terminales señalen únicamente la medida de fachada, la única que varía con valores comprendidos entre los 12 y 15 p.r. ${ }^{21}$. Uno de ellos destaca por haber conservado una pareja de cipos, in situ, que delimitan un frente de 3,60 m. Una medida que corrobora la peditura señalada en las inscripciones gemelas presentes en ambos: L. P. XII / V.I. C. Nos encontramos, pues, ante un acotado de planta cuadrangular, perteneciente a un personaje del que sólo conservamos sus iniciales, probablemente, Vibius Iunius/Iulius, de cognomen difícil de precisar $^{22}$.

Aunque es conocida la existencia de inscripciones con indicación de las medidas del locus sepulturae, sin

21. Un procedimiento análogo se observa en un conjunto de recintos de la via Celimontana, en Roma (Hesberg 2005: 65-67).

22. De la necrópolis de Aquileium procede un interesante y numeroso conjunto de inscripciones funerarias con indicación de la pedatura que se hacen acompañar del nombre del difunto en genitivo o de la abreviatura del mismo reducida a las iniciales del tria nomina (Zaccaria 2005: 201), como en este caso. Inscripciones donde se conservan las iniciales onomásticas se conocen, también, en las necrópolis de Altinum (Cresci 2005: 305, 312, nota 1). 


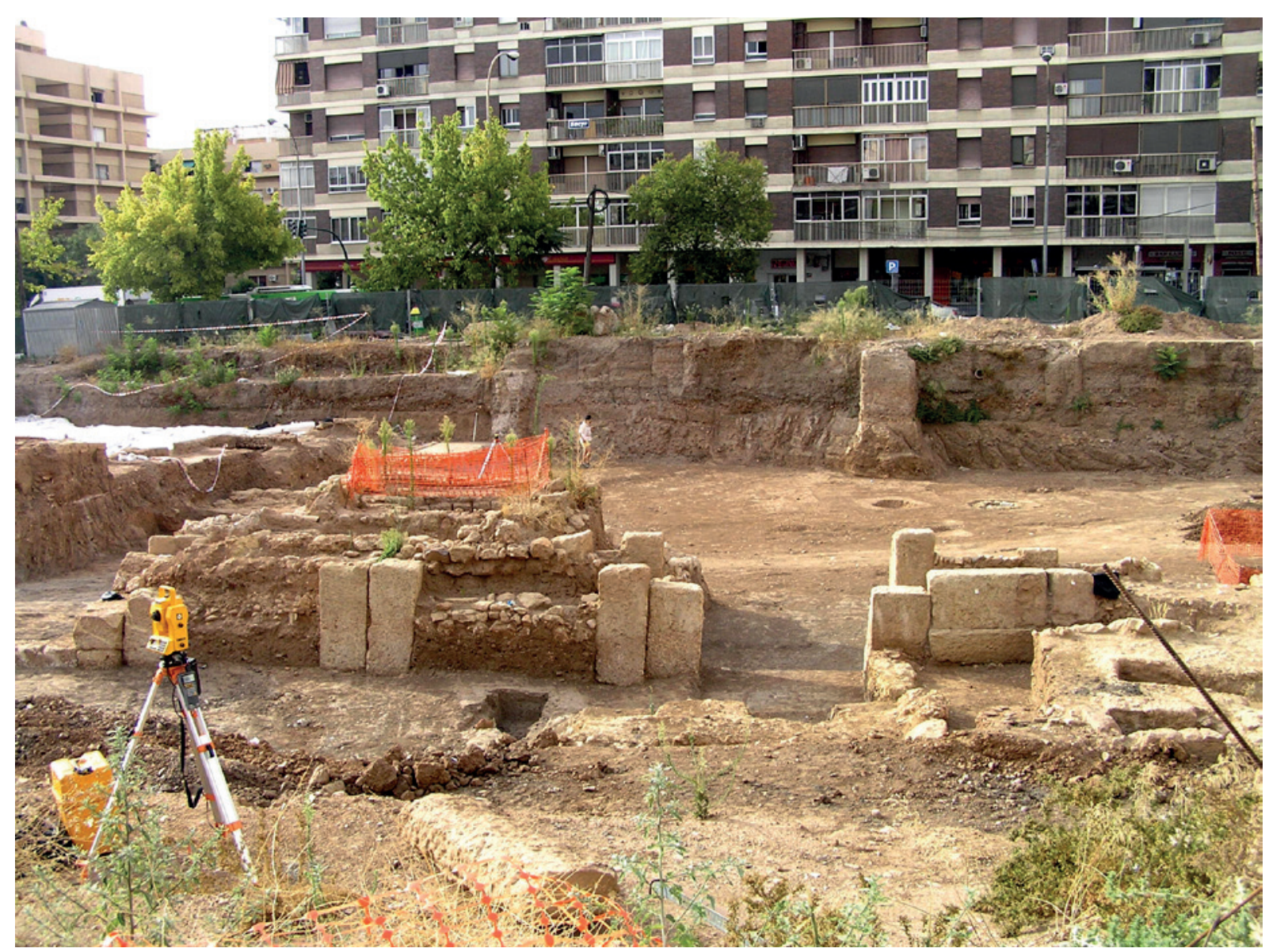

Figura 7. Vista general de la excavación de la Avda. de las Ollerías

ninguna otra referencia a las personas allí enterradas, lo cierto es que en Hispania la mayoría de las veces quedan incluidas en los propios epitafios (Rodríguez Neila 1991: 68 ss.). En este caso, el hecho de que el nombre del propietario aparezca abreviado podría sugerir la existencia de otros dos cipos con los datos del difunto en la fachada meridional, o bien la presencia de una inscripción funeraria fijada sobre algún monumento funerario y perfectamente visible desde el exterior. Así, para el recinto de Licinius Acutus y su esposa, en la Gallia meridional, se ha sugerido la ubicación de cipos terminales con indicación de las medidas del terreno en sus cuatro esquinas y la ubicación de las estelas referentes al matrimonio en el interior del mismo (Christol y Janon 2002: 121 ss.).

De otra parte, resulta frecuente la existencia de cipos gemelos ubicados en el frente del edificio, recurriendo para la parte trasera a soportes de madera, cipos anepigráficos o hitos con la única referencia a las dimensiones del área funeraria (Luca 2005: 85), tal como se comprueba en otro recinto de esta misma necrópolis (Fig. 8). Normalmente, la pareja de cipos dispuesta en la fachada principal presenta la fórmula onomástica completa y la secundaria las iniciales de los nombres y/o la indicación de las medidas del área funeraria (Zaccaria 2005: 201, fig. 10). Esto lleva a plantear la posible identificación de la hasta ahora interpretada como vía funeraria con el "campo de los muertos", destinado a enterramientos más sencillos. De tal forma que el conjunto excavado en la Avda. de las Ollerías no correspondería al frente, sino a la parte trasera de los recintos ${ }^{23}$.

23. Así ocurre en el sector funerario excavado en la via Sacra de Interamnia (Savaini y Torrieri 2002), donde fueron localizados una serie de acotados funerarios contiguos que acogen en su interior monumentos "a dado" o en forma de ara. En el frente fueron colocados uno o dos cipos con el nombre del difunto (o del pater familias), así como las dimensiones de la propiedad (Savaini y Torrieri 2002: 55 ss.). Esta alineación de monumentos abre a la vía principal; sin embargo, en la parte posterior se localiza el denominado "campo 


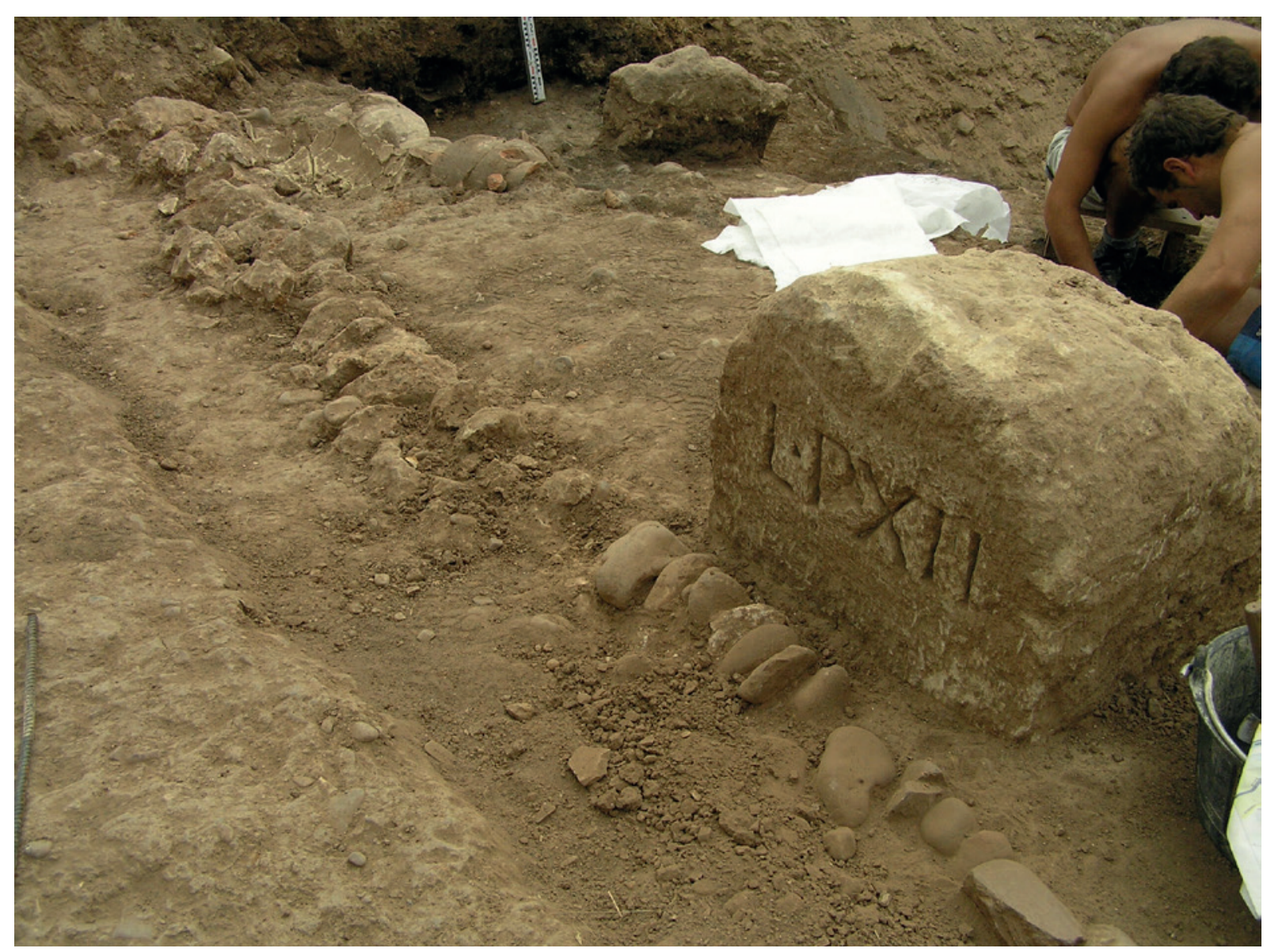

Figura 8. Restos de un recinto funerario con cipo en una de sus esquinas

Con nuestro trabajo hemos pretendido justificar la importancia de las revisiones historiográficas, con especial atención a las fuentes escritas de carácter local. El acceso y ordenamiento de toda esta información ha permitido reconstruir, incluso, la fisonomía original de un tramo de la via Corduba-Hispalis, la cual debió funcionar como una verdadera Grabstrasse ya desde el siglo I a.C., alcanzando su máximo esplendor durante los primeros siglos del Imperio (Murillo y Carrillo 1999: 368). Su característica principal parece ser la de una estricta organización topográfica a través de parcelas previamente establecidas entre las que se sitúan enterramientos de carácter más sencillo, que habrían compartido su espacio con otras instalaciones, industrias y vertederos (Ruiz Osuna 2005: 102). Pero, hemos de tener en cuenta que el estudio y exposición de datos relativos a hallazgos y excavaciones antiguas, carentes en

de los muertos", destinado a sepulturas en fosa simple (Savaini y Torrieri 2002: 48 ss.) muchos casos de una metodología exhaustiva y poco precisos en general, no tienen sentido por sí solos, de ahí el imprescindible cotejo con la realidad arqueológica actual.

\section{BIBLIOGRAFÍA}

ABAD, L.; BENDALA, M. (1985): "Los sepulcros turriformes de Daimuz y Villajoyosa: dos monumentos romanos olvidados", Lucentum IV: 147-184.

ARANEGUI, C. (1995): "Los monumentos funerarios romanos descubiertos en Edeta(Llíria, Valencia)", Saguntum 29. Homenatga a la Profa. Dra. Milagro Gil-Mascarell Boscá, vol. I: 197-210.

ARCE, J. y OLMOS, R. (coords.) (1991): Historiografía de la Arqueología y de la Historia Antigua en España (siglos XVIII-XX), Madrid.

BAENA, M ${ }^{a}$ D. (1989a): Notificación del robo de una urna cineraria de terracota acaecido en el solar $n^{\circ}$ 
14 de la Avenida de las Ollerías (Córdoba) durante el desarrollo de una IAU. Dirigida al Sr. Delegado Provincial de la Consejería de Cultura de la Junta de Andalucía en Córdoba. Depositada en la Delegación Provincial de Cultura de la Junta de Andalucía. Córdoba. Sin paginar.

BAENA, M ${ }^{\mathrm{a}}$ D. (1989b): Informe. Intervención Arqueológica de Urgencia en Avda. de las Ollerías $n^{\circ} 14$ (antiguo Garaje "San Cayetano"), Córdoba. 1989. Depositado en la Delegación Provincial de Cultura de la Junta de Andalucía. Córdoba.

BAENA, L. y BELTRÁN, J. (2002): Las esculturas romanas de la provincia de Jaén, Murcia.

BEJARANO, A. M. (2000): “Intervención arqueológica en al antiguo solar de Campsa. Espacio funerario de época altoimperial", Mérida. Excavaciones arqueológicas, 1998. Memoria: 305-331.

BELTRÁN FORTES, J. (2000): "Mausoleos romanos de Torreparedones (Castro del Río/Baena, Córdoba): sobre la 'Tumba de Pompeyos' y otro posible sepulcro monumental”, Habis 31: 113-136.

BELTRÁN FORTES, J. (2002): "Esculturas romanas desaparecidas de la provincia de Jaén, según el “Catálogo de Monumentos Históricos y Artísticos" de Enrique Romero de Torres", Habis 33: 459-486.

BELTRÁN FORTES, J. y BAENA DEL ALCÁZAR, L. (1996): Arquitectura funeraria romana de la Colonia Salaria (Úbeda, Jaén). Ensayo de sistematización de los monumenta funerarios altoimperiales del alto Guadalquivir, Sevilla.

BELTRÁN, J. y GASCÓ, F. (eds.) (1993): La Antigüedad como argumento. Historiografía de Arqueología e Historia Antigua de Andalucía, Sevilla.

BENDALA, M. (1972): "Los llamados 'Columbarios' de Mérida", Habis 3: 223-254.

CALZA, G. (1940): La necrópoli del Porto di Roma nell'Isola Sacra, Roma.

CANCELA, Ma L. (1993): "Elementos decorativos de la arquitectura funeraria de la Tarraconense oriental", I Reunión sobre Escultura Romana en Hispania, Mérida.

CANCELA, M ${ }^{\mathrm{a}}$ L. (2002): “Aspectos monumentales del mundo funerario hispano", en D. Vaquerizo (ed.), Espacios y Usos funerarios en el Occidente Romano, Vol. I: 163-180. Córdoba.

CARMONA, S.; MORENO, M.F. y BERMÚDEZ, J.M. (1997): Informe de la Intervención Arqueológica de Urgencia en calle Adarve, $n^{\circ} 2$ (Córdoba). Depositado en la Delegación Provincial de Cultura de la Junta de Andalucía. Córdoba.

CHABRET, A. (1888): Sagunto: su historia y sus monumentos, Tomo II, Barcelona.
CHRISTOL, M.; JANON, M. (2002): “Épigraphie et espaces funéraires en Gaule méridionale", en C. Landes (ed.), La mort des notables en Gaule romaine, Catalogue de l'exposition, Lattes.

CRESCI, G. (2005): "Recinto sepolcrali altinati e messaggio epigrafico", en G. Cresci Marrone y M. Tirelli, "Terminavit sepulcrum": i recinto funerari nelle necropoli di Altino: atti del convengo, Venezia, 3-4 dicembre 2003: 305-324. Quasar.

DÍAZ-ANDREU, M. y MORA, G. (coords.) (1997): La Cristalización del Pasado: Génesis y Desarrollo del Marco Institucional de la Arqueología en España, Málaga.

DÍAZ DE RIBAS, P. (1627): De las antigüedades y excelencias de Córdoba, Córdoba.

ESTÉVEZ MORALES, J. A. (2000): “Intervención arqueológica en la obra de construcción de un colector de aguas (canal) en la barriada de $\mathrm{M}^{\mathrm{a}}$ Auxiliadora. Excavación arqueológica de un gran mausoleo", Mérida, Excavaciones Arqueológicas 1998, Memoria: $385-411$.

FLORIANI SQUARCIAPINO, M. (coord.) (1958): Scavi di Ostia. III. Le Necropoli. Parte I. Le tombe di etá repubblicana e augustea, Roma.

GARCÍA MATAMALA, B. (2002-2003): "Enterramientos de tradición indígena en Corduba", A.A.C 13-14: 251-278.

GARCÍA Y BELLIDO, A. (1949): Esculturas Romanas de España y Portugal, 2 vols., Madrid.

GARCÍA Y BELLIDO, A. (1963): "Sarcófago cristiano hallado en Córdoba en 1962”, AEspA XXXVI: 170177.

GASCÓ, F. y BELTRÁN, J. (Eds.) (1995): La Antigüedad como argumento II. Historiografia de Arqueología e Historia Antigua de Andalucía, Sevilla.

GONZÁLEZ MARTÍN, C. (1992): Informe final de IAU C/ Adarve esquina Ollerías. Depositado en la Delegación Provincial de Cultura de la Junta de Andalucía. Córdoba. Sin paginar.

HERNÁNDEZ VERA, J. A.; ARIÑO GIL, E.; MARTÍNEZ TORRECILLA, J. M. y NÚÑEZ MARCÉN, J. (1999): "La presa y el ninfeo del Sotillo (Alfaro, La Rioja): un conjunto monumental en la vía de Italia in Hispanias", Zephyrus LII: 239-260.

HESBERG, H. von (1994): Monumenta. I sepolcri romani e la loro architettura, Milano.

HESBERG, H. von (2005): "Il recinto nelle necropoli di Roma in età Republicana: origine e diffusione", en G. Cresci Marrone y M. Tirelli, "Terminavit sepulcrum": i recinto funerari nelle necropoli di Altino: atti del convengo, Venezia, 3-4 dicembre 2003: 59-75. Quasar. 
IBÁÑEZ, A. et alii (1990): Intervención Arqueológica de Emergencia. Red Arterial Ferroviaria de Córdoba. Informe depositado en la Delegación Provincial de Cultura de la Junta de Andalucía. Córdoba. Sin paginar.

KOCKEL, V. (1993): Portratreliefs stadromishcer Grabbauten, Mainz am Rhein.

LIÉBANA, J. L. y RUIZ, A. (2006): "Los monumentos funerarios de la Plaza de la Magdalena: un sector de la necrópolis oriental de Corduba", A.A.C 17, vol. I: 297-324.

LÓPEZ JIMÉNEZ, A. (2006): Informe y Memoria. Parcela 4 del Plan Especial SC-2a, 06, Depositado en la Delegación Provincial de Cultura de la Junta de Andalucía. Córdoba.

LÓPEZ LÓPEZ, I. (1998): Estatuas togadas y estatuas femeninas vestidas en colecciones cordobesas. Córdoba

LUCA, G. (2005): "Definizione e misurazione dello spazio funerario nell'epigrafia reppubliana e protoimperiale di Roma", en G. Cresci Marrone y M. Tirelli, "Terminavit sepulcrum": i recinto funerari nelle necropoli di Altino: atti del convengo, Venezia, 3-4 dicembre 2003, Quasar.

MARAVER Y ALFARO, L. (1863): Historia de Córdoba desde los más remotos tiempos hasta nuestros días, Córdoba.

MARFIL RUIZ, P. (1997): “Intervención Arqueológica de Emergencia en el $\mathrm{n}^{\circ} 14$ de la Avenida de las Ollerías (Córdoba). 1/7/90 a 31/8/90", A.A.A.'1993, tomo III: $149-160$.

MÁRQUEZ MORENO, C. (1998): La decoración arquitectónica de Colonia Patricia. Una aproximación a la arquitectura y urbanismo de la Córdoba romana, Córdoba.

MELCHOR GIL, E. (1995): Vias romanas de la provincia de Córdoba, CajaSur, Córdoba.

MORALES Y PADILLA, A. (1662): Historia de Córdoba, Córdoba.

MURILLO, J. F. y CARRILLO, J. R. (1999): “Aspectos de la monumentalización de las necrópolis de Colonia Patricia. El monumento funerario de Puerta de Gallegos", en J. González (ed.), Ciudades privilegiadas en el Occidente romano: 365-378. Sevilla.

MURILLO, J. F. et alii (1998): Informe de la I.A.U. en el Vial Norte del Plan Parcial Renfe, Depositado en la Delegación Provincial de Cultura de la Junta de Andalucía. Córdoba. Sin paginar.

PENCO, F. (1997a): Informe final de resultados sobre la Intervención Arqueológica de Urgencia desarrollada en el solar urbano situado en la calle de "El Avellano, 13" (Córdoba). Depositado en la Delegación Provincial de Cultura de la Junta de Andalucía. Córdoba. Sin paginar.
PENCO, F. (1997b): Memoria final del Seguimiento Arqueológico en C/ El Avellano, 13 de Córdoba (3 de marzo-12 de marzo de 1997). Depositado en la Delegación Provincial de Cultura de la Junta de Andalucía. Córdoba. Sin paginar.

PENCO, F. (1998a): "Un conjunto funerario de libertos y esclavos de Época Altoimperial excavado en la calle El Avellano, $n^{\circ} 12$ de Córdoba. Una nueva aportación a Colonia Patricia Corduba", Antiquitas 9: 61-77.

PENCO, F. et alii (1993): "Resultados del estudio de la necrópolis romana excavada durante las dos fases de Intervención Arqueológica de Urgencia desarrolladas en la avenida de las Ollerías n ${ }^{\circ} 14$ de Córdoba", Antiquitas 4: 45-56

PENCO, R. (2004): Informe de la A.A.P. del Marrubial, Esq. Poeta Solís y Vázquez Venegas de Córdoba. Depositado en la Delegación Provincial de Cultura de la Junta de Andalucía. Córdoba. Sin paginar.

RAMÍREZ DE ARELLANO, T. (1873): Paseos por Córdoba. O sean apuntes para su historia, Córdoba.

RAMÍREZ DE LAS CASAS-DEZA, L. (1867): Indicador Cordobés. Manuel histórico topográfico de la ciudad de Córdoba, Córdoba.

REMESAL, J. (1979): "La necrópolis Sureste de Baelo", E.A.E. 104, Madrid.

ROA, M. de (1636): Antiguo Principado de Córdoba en la España Ulterior o Andaluz, Córdoba.

RODRÍGUEZ NEILA, J. F. (1991): "Espacios de uso funerario con indicación de medidas en las necrópolis romanas", Conimbriga XXX: 59-94.

ROMERO DE TORRES, E. (1929): "Excavaciones en el Camino de Mesta próximo al arroyo de Pedroches", JSEA, Madrid.

ROMERO DE TORRES, E. (1941): “Tumba romana descubierta en el Camino Viejo de Almodovar (Cordoba)", en J. Martínez Santa-Olalla (ed.), Corona de Estudios que la Sociedad Española de Antropología, Etnografía y Prehistoria dedica a sus Mártires: 323-329. Madrid.

RUANO, F. (1760): Historia General de Córdoba, Córdoba.

RUIZ NIETO, E. (1995): Informe-Memoria de la I.A.U. en Avenida del Brillante, $s / n$, esquinas a $C /$ Goya y Beatriz Enríquez (Córdoba). Depositado en la Delegación Provincial de Cultura de la Junta de Andalucía. Córdoba.

RUIZ NIETO, E. (1996): Informe-Memoria de la IAU en Avenida de El Brillante, $s / n$, esquinas a C/ Goya y Beatriz Enríquez (Córdoba) (Rampa de acceso al solar durante la obra). Depositado en la Delegación Provincial de Cultura de la Junta de Andalucía. Córdoba. 
RUIZ NIETO, E. (1997a): Informe-Memoria de la I.A.U. en C/ Santa Rosa, s/n, esquina con Avda. de los Almogávares (Córdoba). Depositado en la Delegación Provincial de Cultura de la Junta de Andalucía. Córdoba.

RUIZ NIETO, E. (1997b): Informe del Seguimiento arqueológico en el solar sito en la C/ Santa Rosa, s/n, esquina con Avda. de los Almogávares (antiguo cine de verano Santa Rosa). Depositado en la Delegación Provincial de Cultura de la Junta de Andalucía. Córdoba. Sin paginar.

RUIZ NIETO, E. (1999a): Informe de la Intervención Arqueológica de Urgencia en C/ San Pablo, 17 (Córdoba). Depositado en la Delegación Provincial de Cultura de la Junta de Andalucía. Córdoba.

RUIZ NIETO, E. (1999b): Informe del seguimiento arqueológico en el solar sito en la C/ San Pablo, 17 (Córdoba). Depositado en la Delegación Provincial de Cultura de la Junta de Andalucía. Córdoba.

RUIZ OSUNA, A. (2005): "La via sephulcralis occidental: un ejemplo de monumentalización funeraria en Colonia Patricia Corduba", A.A.C 16: 79-104

RUIZ OSUNA, A. B. (2007): La monumentalización de los espacios funerarios en Colonia Patricia Corduba (Ss. I a.C. - II d.C.). Arqueología Cordobesa 16, Córdoba.

SALINAS, J. M. (2004a): Informe-Memoria del Plan Especial Manzana Banesto. SR-13. Córdoba. Depositado en la Delegación Provincial de Cultura de la Junta de Andalucía. Córdoba.

SALINAS, J. M. (2004b): Informe-Mermoria del Plan Especial Manzana Banesto. SR-13. Córdoba. Sector 1, 3 vols. Depositado en la Delegación Provincial de Cultura de la Junta de Andalucía. Córdoba.

SÁNCHEZ DE FERIA, B. (1772): Palestra Sagrada o Memorial de los Santos de Córdoba, Córdoba.

SÁNCHEZ MADRID, S. (2002): Arqueología y Humanismo. Ambrosio de Morales. Arqueología Cordobesa 4, Córdoba.

SÁNCHEZ, S.; VAQUERIZO, D. (e.p.)

SANTOS GENER, S. (1947): "Museo Arqueológico de Córdoba", MMAP VII, 1946, Madrid.

SANTOS GENER, S. (1950): "Museo Arqueológico de Córdoba", MMAP IX-X, 1948-1949, Madrid.

SANTOS GENER, S. (1955): Memoria de las excavaciones del Plan Nacional, realizadas en Córdoba (19481950), Ministerio de Educación Nacional, Comisaría General de Excavaciones Arqueológicas, Madrid.

SAVAINI, V. y TORRIERI, V. (2002): La via sacra di Intermnia alla luce dei recenti scavi, Chieti.
SILLIÉRES, P. (1997): Baelo Claudia. Una ciudad romana de la Bética, Madrid.

STYLOW, A. U. (2002): "La epigrafía funeraria en la Bética", en D. Vaquerizo (ed.), Espacios y usos funerarios en el Occidente Romano: 353-368. Córdoba.

T'EDA (Taller Escola d'Arqueología) (1987): Els enterraments del Parc de la Ciutat: problemàtica funerária de Tàrraco, Memoria d'Excavación, 1, Tarragona.

VAQUERIZO, D. (1996): "Hipogeo monumental con recinto funerario (Necrópolis Septentrional)", en D. Vaquerizo (coord.), Córdoba en tiempos de Séneca: 194-199. Córdoba.

VAQUERIZO, D. (2001a): "Recintos y Acotados funerarios en Colonia Patricia Corduba", Madrider Mitteilungen 43: 169-205.

VAQUERIZO, D. (2001b): "Formas arquitectónicas funerarias de carácter monumental en Colonia Patricia Corduba", AEspA 74: 131-160.

VAQUERIZO, D. (2002): "Espacio y usos funerarios en Corduba", en D. Vaquerizo (ed.), Espacios y Usos funerarios en el Occidente Romano: 143-200. Córdoba.

VAQUERIZO, D. (en prensa): "Hvmatio et crematio in Hispania. Mos Cordubensivm (Ss. II a.C. II d.C.)", Colloquio Internazionale sulle tombe ad inhumacione nelle province settentrionali et occidentali dell'Impero Romano dal $I^{o}$ al III ${ }^{\circ}$ sec. d.C., Francoforte, 19 e 20, novembre 2004.

VARGAS, S. (2002): "El conjunto funerario de La Constancia (Córdoba). Ajuares y cronología”, en D. Vaquerizo (ed.), Espacio y Usos funerarios en el Occidente Romano: 297-310.

VERZÁR-BASS, M. (2005): "Nota sui recinto funerari decorati in Cisalpina Orientale", en G. Cresci Marrone y M. Tirelli, "Terminavit sepulcrum": i recinto funerari nelle necropoli di Altino: atti del convengo, Venezia, 3-4 dicembre 2003, Quasar.

VICENT, A. M". (1972-74): "Nuevo hallazgo en una necrópolis romana de Córdoba", AEspA 45-47: 113-124.

VICENT, A. Ma . y SOTOMAYOR, M. (1965): “Memoria de las excavaciones realizadas en la necrópolis romana de Córdoba del 22 de septiembre al 9 de octubre de 1963", NAH VII: 209-210.

ZACCARIA, C. (2005): "Recinto funerari aquileisi: il contributo dell'epigrafia", en G. Cresci Marrone y M. Tirelli, "Terminavit sepulcrum": i recinto funerari nelle necropoli di Altino: atti del convengo, Venezia, 3-4 dicembre 2003: 195-223. Quasar. 